\title{
Prognose da produção de cachaça orgânica na região de Araras
}

\section{Prognosis of organic sugar cane spirit production in the Araras region}

\author{
Luiz Antonio Correia Margarido ${ }^{1 *}$; Paulo Roberto Beskow ${ }^{1}$; \\ Jorge José Corrêa Lopes ${ }^{1}$; Clóvis Parazzi ${ }^{1}$; Davi Guilherme Gaspar Ruas ${ }^{1}$
}

\begin{abstract}
Resumo
Apesar da importância econômica e social da aguardente de cana-de-açúcar ou cachaça, são escassos os trabalhos encontrados na literatura que estabelecem comparações entre as características agroindustriais da cultura e o perfil do produtor, aliado à preocupação com a qualidade. Esta agroindústria se caracteriza por apresentar significativa quantidade de pequenos produtores que possuem nesta atividade uma forma de geração de renda, trazendo para o País divisas e empregos. Entretanto, produzem de maneira empírica e rudimentar, baseados no senso comum ou informações repassadas de pai para filho. Foi feito um levantamento preliminar visando caracterizar o perfil das propriedades produtoras de aguardente de cana-de-açúcar da região de Araras, associando-as à viabilidade de obter-se um produto de qualidade com características orgânicas. A região de Araras apresenta um perfil característico do setor, onde a grande maioria trabalha na informalidade, sem registro no Ministério da Agricultura e comercializa sua produção no local. As condições de processamento da cana-de-açúcar são rudimentares e a maioria dos produtores utiliza o fogo direto no alambique, usando lenha como combustível. Em relação a uma possível produção de cachaça orgânica a principal dificuldade está no setor agrícola, devido à forte dependência do uso de adubos químicos solúveis e herbicidas. A produção de cachaça orgânica pode ser uma alternativa viável e atrativa.
\end{abstract}

Palavras-chave: Cachaça, aguardente de cana, cachaça orgânica, qualidade

\begin{abstract}
In spite of social and economic value of the Brazilian sugar cane spirit or cachaça, there are few studies about the parameters of agroindustrial of sugar cane and the profile of the producers, along with concern for quality. This agro-industry has significant number of small producers with it's activity one way to obtain an income, bringing employments and foreign exchange to the country. However, these producers manufacture empirical and rudimental way, based on common sense or information by father or son. The aim of the study was to characterize the profile of the producers of sugar cane spirit or cachaça of the region of Araras, linked them to the viability of obtaining a products of high quality using organic methods. As result of this study was evidenced that the region of Araras shows the same characteristic profile of this sector, where a large majority work in informal conditions, without certificate on Agriculture Ministry and sell its production in local markets. The conditions of manufacturing juice of sugar cane are very rudimentary, where a large majority of producers with simple distillations apparatus. Relatively to the possibility of production of organic sugar cane spirit or cachaça, the main difficulty is located on the rural area, caused by the strong dependence on soluble chemical fertilizers. The production of organic sugar cane spirit or organic cachaça would be one alternative sufficient practicable and attractive.
\end{abstract}

Key words: Cachaça, sugar cane spirit, organic cachaça

\footnotetext{
1 Professores Associados do Departamento de Tecnologia Agroindustrial e Sócioeconomia Rural (DTAiSER)/UFSCar - Centro de Ciências Agrárias - campus de Araras. Cx postal 153 - CEP: 13600-970 Araras SP - e-mail respectivos: marga@cca.ufscar.br; beskow@cca.ufscar.br; parazzi@cca.ufscar.bre ruas@cca.ufscar.br

* Autor para correspondência
} 


\section{Introdução}

A aguardente de cana é a bebida com graduação alcoólica de $38 \%$ (trinta e oito por cento) a 54\% (cinqüenta e quatro por cento), em volume, a $20^{\circ} \mathrm{C}$ (vinte graus Celsius), obtida pela destilação simples do mosto fermentado do caldo de cana-de-açúcar (Saccharum officinarum), podendo ser adicionada de açucares até $6 \mathrm{~g} / \mathrm{L}$ (seis gramas por litro), expressos em sacarose. Já cachaça é a denominação típica e exclusiva da aguardente de cana produzida no Brasil, com graduação alcoólica de 38\% (trinta e oito por cento) a $48 \%$ (quarenta e oito por cento), em volume, a $20^{\circ} \mathrm{C}$ (BRASIL, 2005).

Segundo o Serviço de Apoio às Micro e Pequenas Empresas (2005), estima-se que existam mais de 25.000 estabelecimentos produtores de cachaça no Brasil, estando a maioria destes na informalidade e representam quase $36 \%$ da produção nacional de cachaça. Esta produção é totalmente consumida no mercado interno. López (2003) analisando a venda da cachaça brasileira no exterior descreve que "mesmo as exportações representando apenas 1\% da produção total de cachaça no País (1,3 bilhão de litros), tiveram um incremento de $33 \%$ em 2002, em comparação ao ano anterior".

Silva (2007), analisando o mercado externo de cachaça cita que o Brasil não explora adequadamente o potencial desse produto e acrescenta ainda que em 1996 a receita de exportação deste produto foi de 9,5 milhões de dólares e em 2005 foi de 12,3 milhões de dólares, um aumento tímido considerando o período de uma década. Ainda segundo o mesmo autor, parte expressiva deste aumento se deve à elevação do preço do produto, já que a quantidade cresceu pouco, ou seja, de 8,8 milhões a 10,3 milhões de unidades, no mesmo período. A receita das exportações cresceu $29 \%$ e a quantidade aumentou em $17 \%$.

Existem atualmente nichos de mercado que procuram produtos diferenciados. Esse mercado, no caso da cachaça, prioriza principalmente uma escala de produção artesanal, cuja qualidade sensorial do produto obtido dificilmente é conseguida em escala industrial. $\mathrm{O}$ aumento da produção de cachaça em pequenas propriedades pode ser difundido a médio e curto prazo, visando aproveitar esse mercado. Outro tipo de nicho de mercado que vem crescendo a taxas bastante elevadas é o dos produtos certificados como orgânicos. Esses produtos englobam tanto aqueles in natura como àqueles processados. Nesse mercado, a cachaça orgânica pode despontar com destaque na pauta de exportação dos produtos orgânicos.

A agricultura orgânica já é bastante conhecida no mercado interno, mas é no externo que existe um maior potencial. O mercado internacional de orgânicos movimenta por ano em torno de US\$ 40 bilhões e no Brasil estima-se cerca de US\$ 250 milhões, com crescimento de $20 \%$ ao ano (LIU, 2007).

Para ser considerado orgânico o produto precisa atender as normas que são definidas pelo Ministério da Agricultura, conforme o recente decreto $n^{\circ} 6.323$ (BRASIL, 2007) que regulamenta a produção orgânica no Brasil. O mercado de produtos orgânicos é mais exigente do que o mercado convencional, e os produtos obtidos seguem normas especificas tanto na produção agrícola como no processamento industrial.

Para a produção da cachaça orgânica é necessário que a cana-de-açúcar também seja cultivada no sistema orgânico. A cana de açúcar (Saccharum spp), matéria prima para a produção da cachaça, por ser altamente eficiente na conversão de energia solar em matéria orgânica e ter boa capacidade de prevenção da erosão do solo atende as características desejáveis para se produzir de maneira orgânica (MARGARIDO et al., 2005). A produção de cachaça orgânica nas pequenas propriedades, locais onde hoje está instalada a maioria dos alambiques, permite agregar um valor ao produto, elevando de maneira significativa a receita, sem custos adicionais expressivos.

A aguardente de cana-de-açúcar contém, além do etanol e da água, dezenas de compostos orgânicos, oriundos do processo produtivo e referidos como 
compostos secundários (acidez volátil, aldeídos, ésteres totais, álcoois superiores). A natureza e proporção desses compostos são caracterizadas em diferentes níveis, variáveis em função da qualidade da matéria-prima, da fermentação, do tipo de destilador utilizado (alambiques ou colunas) e do tempo de envelhecimento (MAIA, 1994), com influência direta na qualidade do produto. Outros compostos aparecem como contaminantes na aguardente de cana, tendo como destaque o cobre e o metanol. O metanol, por exemplo, é um álcool indesejável na aguardente, mesmo em doses muito pequenas, a sua origem está associada à degradação da pectina, quando presente na cana. O cobre é outro composto inorgânico indesejável. A contaminação de aguardentes ocorre em conseqüência do acúmulo do azinhavre nas paredes dos destiladores, o qual é solubilizado na aguardente. Esse tipo de contaminação é bastante comum em alambiques de cobre, e pode depreciar bastante o produto. Conforme AZEVEDO et al (2003), foram constatadas contaminações excessivas de cobre em 6,7\% das amostras analisadas no Estado de Minas Gerais, que se encontravam acima do limite permitido pela legislação.

Em produto de qualidade, orgânico ou não, os problemas citados não podem ocorrer e eles devem ser evitados, mediante a aplicação de boas práticas de fabricação.

Com o objetivo de estudar a viabilidade da produção de cachaça orgânica na região de Araras - SP fez-se preliminarmente, um levantamento para caracterizar o perfil das propriedades produtoras e avaliar a qualidade da aguardente produzida.

\section{Metodologia}

A primeira atividade foi quantificar os possíveis produtores de cachaça ou aguardente na região. Para isto, foi necessário delimitar a área de estudo, aqui denominada de Região de Araras, que foi definida como o município de Araras e aqueles que possuem divisa física com o mesmo. A denominada região engloba a área dos municípios de Araras, Conchal, Corumbataí, Engenheiro Coelho, Iracemápolis, Leme, Limeira, Mogi Guaçu e Rio Claro.

O levantamento de campo foi feito com o apoio dos técnicos da Secretaria da Agricultura do Estado, lotadosnas Casas daAgricultura da Coordenadoria de Assistência Técnica do Estado de São Paulo (CATI). Foram aplicados 19 (dezenove) questionários aos produtores de aguardente ou cachaça que estavam operando, descartando os possíveis alambiques que estavam inativos. Além do levantamento realizado foi coletada uma amostra da cachaça produzida na safra anterior. Nessas amostras foram feitas análises físico-químicas visando avaliar a sua qualidade, realizadas de acordo com o previsto em decreto federal (BRASIL, 1997), ou ainda segundo as recomendações da Associação Brasileira de Normas Técnicas (1997). Foram feitas as seguintes determinações: cobre por espectrofotometria de absorção atômica; $\mathrm{pH}$ em potenciômetro digital Tecnopon mPA 210; etanol em correlação com a densidade, obtida em densímetro digital Anton Paar (DMA-45); acidez total e a acidez fixa por volumetria, em alíquota de $25 \mathrm{~mL}$ da amostra; e a acidez volátil - obtida pela diferença entre a acidez total e a acidez fixa.

\section{Resultados}

\section{Caracterização da região em estudo}

Segundo o LUPA (Levantamento das Unidades ProdutivasAgrícolas) descrito porPINO et al.(1997), os municípios que englobam a região estudada possuem uma área total de 299.194 hectares, em 5.944 unidades produtivas, representando $1,50 \%$ da área e 2,14\% das unidades do Estado de São Paulo (Tabela 1). 
Tabela 1. Área (ha) e número de UPAs* da Região de Araras e Estado de São Paulo.

\begin{tabular}{ccc}
\hline Município & Número de UPAs $^{*}$ & Área (hectares) \\
\hline Araras & 895 & $60.419,4$ \\
Conchal & 450 & $11.240,2$ \\
Corumbataí & 588 & $26.247,3$ \\
Engenheiro Coelho & 448 & $9.679,8$ \\
Iracemápolis & 109 & $10.330,8$ \\
Leme & 639 & $38.675,6$ \\
Limeira & 1205 & $44.228,7$ \\
Mogi Guaçu & 836 & $63.762,1$ \\
Rio Claro & 774 & $34.610,1$ \\
\hline Estado de Sáo Paulo & 277.124 & $19.999 .484,5$ \\
\hline
\end{tabular}

*UPAs - Unidades de produção agrícola. Fonte: PINO et al. (1997).

A distribuição da área das unidades produtivas, em estratos, encontra-se na Tabela 2, para os 10 municípios da região e para o Estado de São Paulo, conforme informações do "LUPA" (PINO et al.,1997).

Verificou-se que todos os municípios da região possuem unidades de produção de aguardente (UPAs), e conseqüentemente cultivam cana-deaçúcar, conforme detalhes mostrados na Tabela
3. Da área total das unidades da região, $24,42 \%$ apresentam o cultivo com esta cultura, enquanto que este percentual para o Estado de São Paulo é de $25,30 \%$.

$\mathrm{Na}$ Tabela 4 encontra-se a distribuição dos produtores de cana-de-açúcar e o número de engenhos, conforme constam do 'LUPA', segundo Pino et al. (1997), e o número de engenhos em que foram realizados os levantamentos.

Tabela 2. Distribuição das unidades produtivas em estratos de área (ha), da região e do Estado de São Paulo.

\begin{tabular}{ccccc}
\hline Estrato & \multicolumn{2}{c}{ Região de Araras } & \multicolumn{2}{c}{ Estado de São Paulo } \\
\hline & Número & Área Total & Número & Área Total \\
0 a 1 & 56 & 37,3 & 3.765 & 2428,3 \\
1 a 2 & 147 & 249,6 & 6.018 & 9.468 \\
a 5 & 920 & $3.378,2$ & 30.035 & $110.385,6$ \\
5 a 10 & 1028 & $8.838,9$ & 37.340 & $288.479,4$ \\
10 a 20 & 1638 & $23.749,6$ & 58.778 & $86.7691,2$ \\
20 a 50 & 1291 & $48.660,7$ & 71.070 & $227.4151,1$ \\
50 a 100 & 387 & 31.642 & 31.385 & $223.0217,7$ \\
100 a 200 & 232 & $32.772,4$ & 19.151 & $2.688 .551,8$ \\
200 a 500 & 163 & $49.539,1$ & 13.277 & $4054.429,9$ \\
500 a 1000 & 53 & $40.480,6$ & 4.055 & $2.798 .117,6$ \\
1000 a 2000 & 56 & $25.069,7$ & 1.602 & $2184.519,5$ \\
2000 a $>$ & 29 & $59 . .845,6$ & 648 & $2.491 .044,4$ \\
\hline
\end{tabular}

Fonte: PINO et al. (1997). 
Tabela 3. Número de UPAs, área ocupada com cana-de-açúcar e percentual sobre a área total das UPAs do município.

\begin{tabular}{cccc}
\hline Município & Número de UPAs & Área (hectares) & \% sobre o Total \\
\hline Araras & 395 & $30.354,9$ & 50,24 \\
Conchal & 11 & 212,1 & 1,89 \\
Corumbataí & 222 & $2.823,7$ & 10,76 \\
Engenheiro Coelho & 16 & 642,9 & 6,64 \\
Iracemápolis & 75 & $8.421,1$ & 81,51 \\
Leme & 223 & $18.672,9$ & 48,28 \\
Limeira & 150 & $14.191,2$ & 32,09 \\
Mogi Guaçu & 78 & $10.426,8$ & 16,35 \\
Rio Claro & 400 & $11.578,8$ & 33,46 \\
\hline Estado de São Paulo & 70.111 & $2.886 .312,6$ & 14,43 \\
\hline
\end{tabular}

Fonte: PINO et al.(1997).

Tabela 4. Número de produtores nos municípios da região e de engenhos constante no LUPA e número de engenhos feitos os levantamentos.

\begin{tabular}{cccc}
\hline \multirow{2}{*}{ Município } & \multicolumn{2}{c}{ Posição no LUPA* } & Levantamento*** $^{*}$ \\
\cline { 2 - 4 } & $\mathbf{n}^{\mathbf{0}}$ de Produtores & $\mathbf{n}^{\mathbf{0}}$ de Engenhos & $\mathbf{n}^{\mathbf{0}}$ de Engenhos \\
\hline Araras & 3 & 3 & 4 \\
Conchal & 1 & 1 & 1 \\
Corumbataí & 3 & 3 & 1 \\
Engenheiro Coelho & 4 & 4 & 1 \\
Iracemápolis & 1 & 1 & 1 \\
Leme & 3 & 3 & 3 \\
Limeira & 2 & 2 & - \\
Mogi Guaçu & 4 & 4 & 1 \\
Rio Claro & 1 & 1 & $7 *$ \\
\hline Estado de São Paulo & 1488 & 1537 & - \\
\hline
\end{tabular}

*Fonte: PINO et al. (1997) e Pesquisa de Campo.

**Obs: No município de Rio Claro está incluído um engenho em Ipeúna e dois em Charqueada.

O número de unidades produtoras, por municípios, no levantamento de campo é diferente daquele apresentado pelo LUPA, mas deve-se levar em consideração a defasagem de 09 anos entre os dois levantamentos. Nessa relação estão incluídas duas unidades produtoras de aguardente e álcool, uma no município de Ipeúna e a outra em Mogi Guaçu. Portanto, na discussão a seguir foram consideradas 17 unidades produtoras de aguardente. As outras duas não preenchem as condições do projeto, além de existir uma outra unidade nesta mesma condição, no município de Leme, que não consta no levantamento efetuado. Na região em estudo, também operam 03 unidades de grande porte, produtoras de açúcar e álcool, duas em Araras e uma em Leme.

\section{Caracterização da produção da cana-de-açúcar}

Com o intuito de facilitar a análise visando a conversão do plantio convencional da cultura da cana-de-açúcar para o orgânico, foi elaborada a tabela 5. 


\begin{tabular}{|c|c|}
\hline Permitido & Não Permitido \\
\hline Fosfato Natural & \\
Calagem & Adubos químicos solúveis \\
Cultivo mecânico & Herbicidas \\
Adubação Verde & Inseticidas sintéticos \\
Composto Orgânico & Hormônios \\
Biofertilizantes & Organismos Transgênicos \\
Vinhaça ( orgânica) & Queimada \\
Controle Biológico & \\
& \\
\hline
\end{tabular}

Quadro 1. Relação do que é permitido usar no cultivo da cana orgânica.

Fonte: MARGARIDO (2007).

No quadro acima se tem de maneira resumida as principais diferenças nos sistemas de produção orgânico e convencional.

Dados da pesquisa mostraram que a cana-deaçúcar, matéria-prima para a produção da cachaça, é produzida na propriedade, com exceção de uma que adquire cana de terceiros. Nesse caso, para se produzir cachaça orgânica faz-se necessário a certificação orgânica da cana produzida por terceiros.

Três produtores ainda utilizam a queima da palha da cana integrada ao sistema de produção, principalmente em propriedades de grande porte e um apenas produtor tem conhecimento das variedades que cultiva. No sistema de produção orgânico tanto a queima da cana de açúcar para a colheita quanto a queima da palha após o corte é proibida.

A quantidade de cortes da cana-de-açúcar em uma mesma área varia de 3 a 5 e o preparo do solo para o plantio segue o sistema convencional, ou seja, a maioria dos produtores faz calagem, gradeagem e sulcação, praticas essas toleradas pela agricultura orgânica. Apenas dois produtores realizam o cultivo de milho intercalar a cana-de-açúcar, prática incentivada pela agricultura orgânica, além de outros dois utilizarem adubo orgânico em vez de adubo químico. Treze produtores utilizam herbicidas para o controle de plantas infestantes e adubos químicos solúveis, não toleráveis pelas normas da agricultura orgânica.

Treze produtores utilizam a vinhaça, resíduo da destilação da cachaça, como ferti-irrigação na cultura da cana-de-açúcar ou em outras culturas, como, por exemplo, no cultivo da laranja. Nesse caso, só é permitido o uso da vinhaça para a irrigação na produção de cana e de cachaça orgânica.

Com exceção de um produtor, os demais têm conhecimento sobre a agricultura orgânica e sobre a produção de cachaça orgânica, embora apenas uma propriedade produza cachaça orgânica. A maioria dos produtores mostrou-se interessado na produção orgânica de cachaça, principalmente devido à possibilidade de gerar maiores ganhos na comercialização do produto.

\section{Caracterização da produção da cachaça}

Cerca de 50\% dos produtores preparam o fermento na propriedade, ou seja, utilizam o chamado fermento "caipira". Os demais adquirem esse produto no mercado. Ambos os tipos de fermento são permitidos pelas normas orgânicas. O tempo de fermentação varia de 18 a 72 horas. Somente em 
um dos produtores esse tempo é reduzido para 10 horas. Para a maioria dos produtores o tempo médio de fermentação é de 25 horas. Cinqüenta por cento dos produtores utilizam o sistema de recuperação do fermento, por decantação e/ou centrífugas, e nenhum deles utiliza antibióticos no controle de contaminações, que eventualmente possam ocorrer no processo.

Todos os produtores considerados pequenos usam o alambique de cobre do tipo cebolão, já os de maior capacidade de produção ou que também produzem álcool, utilizam colunas de destilação de aço inox. Quanto ao uso de equipamentos de cobre não existe restrição, desde que o produto final não seja contaminado por esse elemento químico. Quanto ao sistema de destilação, a maioria separa a fração cabeça e cauda, prática essa obrigatória para um produto de melhor qualidade, indiferente de ser orgânico ou não. Foram observados dois casos em que não se realiza nenhum descarte, o que pode comprometer a qualidade do produto. As unidades de processamento de cachaça são propriedades individuais e apenas uma pertence à cooperativa.

\section{Característica da cachaça produzida}

Os produtores de cachaça não têm como rotina a realização de análises químicas detalhadas do produto final, porém cerca de cinqüenta por cento já a fizeram uma vez ou outra.

Com relação ao teor alcoólico do produto final houve variação nos dados fornecidos pelos produtores, uma vez que as informações foram repassadas, em alguns casos, em graus Cartier (medição em desuso) e em outros em graus GayLussac. No entanto com as análises das amostras coletadas verificou-se que a maioria se encontrava abaixo de $38 \%$ GL (v/v), valor mínimo exigido pela legislação atual (Tabela 6).

Em relação ao armazenamento e comercialização da aguardente produzida a maioria dos produtores utiliza tonéis de madeira de diferentes capacidades. Um terço dos produtores possui registro no Ministério da Agricultura, sendo que estes podem comercializar sua produção de forma mais organizada, pois os demais vendem para conhecidos e normalmente comercializados em garrafões.

\section{Qualidade da cachaça produzida}

Os resultados das analises se encontram na Tabela 5 e 6 . As coletas das amostras foram feitas em 18 propriedades.

Em relação aos inorgânicos da cachaça foram analisados o cobre e o ferro. Cerca de quarenta e cinco por cento das amostras analisadas não estavam em conformidade com a legislação, em relação ao cobre, cujo limite máximo é de $5 \mathrm{mg} / \mathrm{L}$ (BRASIL, 2005). O menor valor obtido $(0,4 \mathrm{~g} / \mathrm{L})$ refere-se à cachaça obtida em colunas de destilação de aço inox.

A maioria das amostras de cachaça apresentou teor não detectável de ferro, e apenas uma em quantidade destacável $(4,2 \mathrm{mg} / 100 \mathrm{~mL})$, embora a legislação brasileira não determine limites para esse elemento químico.

A acidez volátil expressa em ácido acético também se encontra dentro do limite aceitável, máximo de $150 \mathrm{mg} / \mathrm{mL}$ de álcool anidro. Entre as amostras analisadas, somente 03 (três) apresentaram valores elevados de acidez volátil, embora não superior a 100mg/100 mL de álcool anidro. Assim sendo, todas as amostras analisadas encontram-se dentro dos padrões fixados pela legislação. 
Tabela 5. Resultados das análises químicas das cachaças coletadas em dezoito propriedades.

\begin{tabular}{ccccccc}
\hline \multirow{2}{*}{ Amostras } & $\begin{array}{c}\mathbf{C u} \\
\mathbf{m g} / \mathbf{L}\end{array}$ & $\begin{array}{c}\mathbf{F e} \\
\mathbf{m g} / \mathbf{1 0 0} \mathbf{~} \mathbf{L}\end{array}$ & $\mathbf{p H}$ & $\begin{array}{c}\text { Ac. Volátil } \\
\mathbf{g} / \mathbf{1 0 0} \mathbf{~ m L}\end{array}$ & $\begin{array}{c}\text { Ac. } \mathbf{F i x a} \\
\mathbf{g} / \mathbf{1 0 0} \mathbf{~ m L}\end{array}$ & $\begin{array}{c}\text { Ac. } \text { Total } \\
\mathbf{g} / \mathbf{1 0 0} \mathbf{~ m L}\end{array}$ \\
\hline 1 & 5,1 & nd & 3,8 & 7,26 & 7,85 & 15,11 \\
2 & 4,6 & nd & 3,9 & 7,48 & 7,83 & 15,31 \\
3 & 0,9 & 1,8 & 4,1 & 2,65 & 4,21 & 6,86 \\
4 & 4,9 & nd & 3,9 & 2,83 & 4,33 & 7,16 \\
5 & 4,6 & nd & 4,0 & 9,64 & 15,72 & 25,36 \\
6 & 3,7 & nd & 3,9 & 2,65 & 5,98 & 8,63 \\
7 & 9,3 & nd & 4,0 & 9,63 & 12,94 & 22,57 \\
8 & 1,5 & nd & 4,5 & 9,67 & 13,55 & 23,22 \\
9 & 6,8 & 0,5 & 3,7 & 4,33 & 5,43 & 9,76 \\
10 & 2,5 & 0,3 & 4,6 & 4,80 & 14,43 & 19,23 \\
11 & 5,5 & nd & 4,4 & 14,68 & 22,89 & 37,57 \\
12 & 6,5 & nd & 4,2 & 36,03 & 49,23 & 85,26 \\
13 & 3,7 & 0,7 & 4,3 & 4,87 & 10,29 & 15,16 \\
14 & 7,0 & nd & 3,5 & 4,93 & 12,56 & 17,49 \\
15 & 8,8 & nd & 3,4 & 31,82 & 38,93 & 70,75 \\
16 & 9,7 & nd & 4,5 & 31,23 & 35,01 & 66,24 \\
17 & 2,4 & nd & 4,2 & 12,04 & 18,65 & 30,69 \\
18 & 0,4 & 4,2 & 4,1 & 8,98 & 12,14 & 21,12 \\
\hline
\end{tabular}

nd - não detectado.

Tabela 6. Resultados das análises químicas das cachaças coletadas em dezoito propriedades.

\begin{tabular}{cccc}
\hline Amostras & $\begin{array}{c}\text { Extrato Seco } \\
\mathrm{g} / \mathrm{L}\end{array}$ & $\begin{array}{c}\text { Grau Alcoólico } \\
\%(\mathrm{v} / \mathrm{v})\end{array}$ & $\begin{array}{c}\text { Densidade } \\
20 / 20^{\circ} \mathrm{C}\end{array}$ \\
\hline 1 & 0,50 & 37,9 & 0,9529 \\
2 & 0,52 & 34,7 & 0,9577 \\
3 & 0,10 & 48,2 & 0,9353 \\
4 & 0,10 & 38,6 & 0,9520 \\
5 & 0,15 & 37,3 & 0,9539 \\
6 & 0,10 & 39,2 & 0,9510 \\
7 & 0,40 & 37,3 & 0,9539 \\
8 & 0,35 & 44,1 & 0,9428 \\
9 & 0,10 & 42,8 & 0,9452 \\
10 & 0,18 & 36,9 & 0,9545 \\
11 & 0,12 & 36,8 & 0,9547 \\
12 & 0,10 & 39,8 & 0,9501 \\
13 & 0,16 & 33,8 & 0,9590 \\
14 & 0,10 & 37,4 & 0,9537 \\
15 & 0,17 & 35,3 & 0,9569 \\
16 & 0,10 & 39,6 & 0,9520 \\
17 & 0,20 & 44,6 & 0,9420 \\
18 & 0,15 & 32,8 & 0,9603 \\
\hline
\end{tabular}


De acordo com a identidade legal da bebida obtida do destilado alcoólico simples do mosto fermentado do caldo de cana-de-açúcar, a aguardente de cana deve possuir uma graduação alcoólica de $38 \% \mathrm{v} / \mathrm{v}$ (trinta e oito por cento em volume) a $54 \% \mathrm{v} / \mathrm{v}$ (cinqüenta e quatro por cento em volume) a $20^{\circ} \mathrm{C}$ (vinte graus centígrados), e a cachaça de $38 \% \mathrm{v} / \mathrm{v}$ (trinta e oito por cento em volume), a $48 \% \mathrm{v} / \mathrm{v}$ (quarenta e oito por cento em volume) a $20^{\circ} \mathrm{C}$ (vinte graus centígrados) (BRASIL, 2005). Assim sendo, das amostras analisadas 55\% não possuem a graduação mínima exigida para a sua comercialização como aguardente ou cachaça. Apesar disso, entre as amostras que não atendem à legislação atual, 34\% (trinta e quatro por cento) apresentaram valores próximos a $38^{\circ} \mathrm{GL}(\mathrm{v} / \mathrm{v})$, o mínimo exigido pela legislação; as demais amostras em não conformidade, ou seja, 22\% do total analisado apresentaram valores abaixo de $36^{\circ} \mathrm{GL}(\mathrm{v} / \mathrm{v})$. Apenas uma das amostras pode ser enquadrada como aguardente de cana, conforme determina a legislação.

Os teores de extratos secos obtidos podem ser considerados normais e sem implicações na qualidade das cachaças analisadas.

\section{Prognose}

A produção de cachaça e aguardente na Região de Araras apresenta um perfil característico do setor, onde a grande maioria trabalha na informalidade, sem registro no Ministério da Agricultura e comercializa sua produção no local.

$\mathrm{Na}$ maioria das vezes, as condições onde o produto é processado deixam a desejar em termos de assepsia e cuidados com a saúde do trabalhador. A grande maioria utiliza o processo de fogo direto no alambique, queimando lenha nem sempre oriunda de florestas plantadas, como combustível, o que para essa região não é uma prática considerada ecologicamente correta e poderia ser um impedimento para a certificação orgânica. Isto poderia ser facilmente contornado utilizando-se caldeiras de pequeno porte e queimando-se o próprio bagaço da cana como combustível.

A dificuldade encontrada pelos produtores para a produção de cachaça orgânica é advinda do setor agrícola, principalmente pela dependência do uso de adubos químicos solúveis e herbicidas. Esta dificuldade poderia ser superada com o uso de adubos verdes e também de compostos orgânicos feitos na própria propriedade com o bagaço de cana, vinhaça da cachaça ou qualquer outra fonte de matéria orgânica disponível. O incentivo de plantio de culturas intercalares, além de gerar renda, também seria uma prática que diminuiria a competição com plantas espontâneas (mato).

No processo de destilação seria necessário um maior cuidado com a limpeza dos alambiques, visando principalmente uma menor contaminação com cobre e também seria necessário investir em melhoras instalações, sempre visando boas práticas de fabricação.

Apesar das dificuldades encontradas acreditase que a produção de cachaça orgânica, para os produtores de Araras e região, seria uma alternativa bastante atrativa e apropriada para o pequeno produtor, podendo agregar valor à sua produção e ainda aliar a produção de cachaça ao turismo rural, que é um segmento que está em expansão no estado de São Paulo e acredita-se que a Região de Araras, pelas suas características, se adequaria muito bem a essa proposta. 


\section{Referências}

AZEVEDO, S. M.; CARDOSO, M. G.; PEREIRA, N. E.; RIBEIRO, C. F. S.; SILVA, V. F.; AGUIAR, F, C. Levantamento da contaminação por cobre nas aguardentes de cana-de-açúcar produzidas em Minas Gerais. Ciência e Agrotecnologia, Lavras, v. 27, n. 3, p. 618-24, maio/ jun., 2003.

ASSOCIAÇÃO BRASILEIRA DE NORMAS TÉCNICAS. NBR 13921: aguardente de canadeterminação de cobre. Rio de Janeiro: ABNT, 1997.

BRASIL. Ministério da Agricultura, Pecuária e Abastecimento. Instrução Normativa $\mathrm{n}^{\circ} 13$ de 29 de junho de 2005. Diário Oficial da União, Brasília, DF, 30 jun. 2005. Seção 1, p. 3-4.

BRASIL. Ministério da Agricultura, Pecuária e Abastecimento. Decreto n. 2.314, de 04 de setembro de 1997. Diário Oficial da União, Brasília, DF, 05 set. 1997.

BRASIL. Ministério da Agricultura, Pecuária e Abastecimento. Decreto n. 6.323, de 27 de dezembro de 2007. Diário Oficial da União, Brasília, DF, 27 dez. 2007.

LIU, M. Mercado de orgânicos aguarda regulamentação. Disponível em: $<$ http://www.organicosbrasil.org/ noticias $>$. Acesso em: 07 set. 2007.

LÓPEZ, R. Cachaça amplia potencial de consumo no mercado externo. Engarrafador Moderno, São Caetano do Sul, n. 110, p. 18-24, jul. 2003.
MAIA, A. B. Componentes secundários da aguardente. STAB, Piracicaba, v. 12, n. 6, p. 29-34, 1994.

MARGARIDO, L. A. C. Cana-de-açúcar orgânic. Araras: CCA/UFSCar, 2007. (Palestra apresentada no curso MTA).

MARGARIDO, L.A. C.; RUAS, D. G. G.; LAVORENTI, N. A.; MATSUOKA, S.; BESKOW, P. R.; STOLF, R. Produção orgânica da cana-de-açúcar, açúcar mascavo, melaço e rapadura: uma experiência. Extensão Rural e Desenvolvimento Sustentável, Porto Alegre, v. 1, n. 4, p. 39-43, nov./dez. 2005.

PINO, F. A.; FRANCISCO, V. L. F. S.; TORRES, A. J.; LORENA NETO, B.; CASER, D. V.; BIRAL, M. A. M. (Org.). Levantamento censitário de unidades de produção agrícola do Estado de São Paulo. São Paulo: IEA; CATI; SAA, 1997. $4 \mathrm{v}$.

SERVIÇO DE APOIO ÀS MICRO E PEQUENAS EMPRESAS - SEBRAE. Estudo de viabilidade econômica: simulação da produção de 60 mil litros de cachaça/safra. Belo Horizonte, 2005. Disponível em: $<$ http://www.canabrasil.com.br/component/option,com docman/task,doc_view/gid,9/Itemid,75/>. Acesso em: 23 abr. 2008.

SILVA, C. R. L. Exportação brasileira de cachaça. Análises e Indicadores do Agronegócio, São Paulo, v. 2, n. 4, 4p, abril 2007. 